\title{
A educação pela perspectiva da abordagem das capacitações
}

Géssica Mathias Diniz ${ }^{1}$

Solange Regina Marin ${ }^{2}$

Paulo Ricardo Feistel ${ }^{3}$

\begin{abstract}
Resumo:
O objetivo deste estudo é apresentar a contribuição da Abordagem das Capacitações para a análise do papel desempenhado pela educação na vida dos indivíduos. A educação não só melhora as condições sociais e econômicas dos indivíduos (liberdade instrumental), mas também desenvolve as habilidades de leitura, escrita, argumentação e compreensão, por exemplo, atuando como liberdade intrínseca (liberdade substantiva). A educação torna o indivíduo livre para exercer o controle sobre sua própria vida e realizar o que considera de valor para si (liberdade positiva). A Abordagem das Capacitações, assim, permite compreender que a educação é fundamental para o desenvolvimento da liberdade humana.
\end{abstract}

Palavras-Chave: Educação; Abordagem das Capacitações; Liberdade humana.

The education for perspective of the Capability Approach

\begin{abstract}
:
The aim of this study is to present the contribution of the Capability Approach to the analysis of the role played by education in the lives of individuals. Education not only improves the social and economic conditions of individuals (instrumental freedom), but also develops the skills of reading, writing, reasoning and understanding, for example, acting as an intrinsic freedom (substantive freedom). Education makes the free individual to exercise control over your own life and realize what it considers of value to you (positive freedom). The Capability Approach thus enables us to understand that the education is fundamental to the development of human freedom.
\end{abstract}

Keywords: Education; Capability Approach; Human Freedom.

Classificação JEL: I25; I30.

1 Doutoranda em Desenvolvimento Econômico pelo Programa de Pós-Graduação em Desenvolvimento Econômico (PPGDE/UFPR).E-mail: gessica92eco@gmail.com

2 Professora Adjunta do Departamento de Economia e Relações Internacionais da Universidade Federal de Santa Catarina (UFSC). E-mail: solmarin@gmail.com

3 Professor Adjunto do Departamento de Ciências Econômicas e do Programa de Pós-Graduação em Economia e Desenvolvimento (PPGE\&D) da Universidade Federal de Santa Maria (UFSM). E-mail:prfeistel@gmail.com 


\section{Introdução}

A palavra educar vem do latim educare que significa "conduzir para fora" ou "direcionar para fora". O termo é composto pela união do prefixo ex, que significa "fora", e ducere, "conduzir" ou "levar". A ideia por trás desse significado é de que a educação permite aos indivíduos conhecer o mundo ao seu redor.

A educação, seja ela entendida como aquela obtida na escola, na interação com colegas ou desenvolvida via meios de comunicação, permite aos indivíduos expandirem as suas liberdades, desenvolverem suas habilidades de leitura, escrita e compreensão, qualificando-os para se inserirem no mercado de trabalho e, também, facilita o acesso e a utilização das informações que estão a sua disposição.

Essa diversidade de funções desempenhadas pela educação encaminha a análise para o campo da liberdade, pois a possibilidade de escolher qual ou quais dessas funções realizar corresponde ao exercício da liberdade humana. A relação entre a educação e a liberdade humana remete ao enfoque da Abordagem das Capacitações que adota a liberdade como elemento-chave para a avaliação do bem-estar individual.

A abordagem que foi proposta, inicialmente, por Amartya Sen (1979a, 1985, 2010) e, posteriormente, por Martha Nussbaum (2003, 2011), considera o indivíduo como fim em si mesmo que utiliza os meios a que tem acesso para ser e fazer (being and doing) os funcionamentos que considera de maior valor para si. A união dos diversos funcionamentos forma o conjunto capacitário, o qual corresponde à liberdade de escolha. A proposta de Sen (2003a, 2010) é de que para o desenvolvimento humano ocorrer deve haver a expansão das capacitações, isto é, a ampliação das liberdades individuais.

Ao se considerar a Abordagem das Capacitações e a educação, este trabalho pretende responder ao seguinte questionamento: qual a contribuição da Abordagem das Capacitações na análise dos papéis (instrumental e intrínseco) da educação para a vida dos indivíduos? O objetivo central é apresentar a educação na Abordagem das Capacitações e explorar a relevância da educação não só como instrumento para a expansão da liberdade humana, mas também como um recurso importante pela sua própria existência, por permitir ao indivíduo desenvolver suas habilidades de julgamento e discernimento.

A contribuição da Abordagem das Capacitações para a análise dos papéis intrínseco e instrumental da educação está no enfoque sobre a liberdade humana. A educação permite que o indivíduo realize outros beings and doings valorados ao longo de sua vida, que vão além da sua instrumentalidade. Este estudo caracteriza-se pelo cunho teórico. É desenvolvido com base na pesquisa de referencial pertinente à Abordagem das Capacitações e revisão bibliográfica acerca da relação estabelecida entre a educação e a abordagem.

Para o desenvolvimento desse artigo, foram estruturadas duas seções, além desta introdução e das considerações finais. $\mathrm{Na}$ segunda seção, são descritos o surgimento da Abordagem das Capacitações, o conceito de liberdade que constitui o elemento-chave dessa abordagem e, definidos os funcionamentos, a capacitação e os intitulamentos. A terceira seção é dedicada à discussão sobre a percepção que se tem sobre a educação na Abordagem das Capacitações. 


\section{A Abordagem das Capacitações}

A Abordagem das Capacitações foi apresentada pela primeira vez em 1979 no artigo 'Equality of what?' do economista indiano Amartya Sen ${ }^{4}$. Essa abordagem surgiu como uma proposta alternativa para a análise do bem-estar humano em relação à ideia apresentada pela economia tradicional, na qual se enquadra o Utilitarismo, que adota a utilidade como base informacional. Essa abordagem seria uma extensão da ideia de bens primários de John Rawls ${ }^{5}$, de acordo com o Amartya Sen (1979a, 1993, 2008, 2010).

A economia do bem-estar tradicional toma como base informacional a utilidade para a avaliação do bem-estar dos indivíduos, uma medida subjetiva e restrita. O Utilitarismo não julga as escolhas em termos de seus efeitos sobre os seres humanos, mas pelas suas consequências sobre um aspecto limitado dos indivíduos, a utilidade (SEN, 1997).

Sen (1979b) destaca que uma das características que se sobressai em todas as interpretações utilitaristas, uma regra comum a todas, é o fato de ver a bondade do estado das coisas na soma das utilidades individuais obtidas naquela situação, esse é o resultado utilitarista. Esta definição baseia-se nos requisitos de avaliação utilitarista que são o consequencialismo, o welfarismo e o ranking pela soma (SEN, 2010, p. 84).

A restrição informacional que o welfarismo impõe ao julgamento moral de estados de coisas alternativos (alternatives state of affairs) deve-se a adoção de informações sobre as utilidades pessoais, sem considerar outras informações sobre estes estados (SEN, 1979b, 1990). O ranking pela soma, terceiro componente do Utilitarismo, é observado quando são somadas as utilidades de diferentes pessoas sem avaliar a distribuição do total entre os indivíduos (SEN, 2010).

Seja pela interpretação da escolha, do desejo ou da felicidade, o que se tem é a incompletude das informações. A subjetividade desses estados mentais torna difícil a avaliação de quais critérios estão envolvidos na construção do bem-estar individual e a inconsistência de possíveis comparativos de bem-estar (SEN, 1985). Lionel Robbins, em 1932, destacou a impossibilidade de comparar as magnitudes de satisfação de pessoas diferentes.

Para solucionar o problema de subjetividade do Utilitarismo relacionado

4 Amartya Sen nasceu no ano de 1933 na cidade de Shantiniketan, localizada no estado indiano de Bengala Ocidental. Em 1998, recebeu o Prêmio Nobel de Economia por suas contribuições nas áreas de bem-estar e pobreza.

5 Os bens primários correspondem à uma lista de recursos que o indivíduo quer, esta lista foi definida pelo filósofo político norte-americano John Rawls (1921-2002), que se dedicou ao estudo da justiça com vistas a equidade. Segundo Rawls (1988), os bens primários estão distribuídos em cinco categorias, são elas: os direitos básicos e liberdades; liberdade de movimento e livre escolha de ocupação; poderes e exercício de ofícios e posições de responsabilidade; renda e riqueza e; as bases sociais do autorrespeito. 
a mensuração de estados mentais, Sen (1985) expôs a necessidade de um critério objetivo para a avaliação do bem-estar, alinhado com Rawls (1988). Para Scanlon (1975 apud Sen, 1985, p. 196) esse critério deveria ser independente dos gostos e dos interesses das pessoas. A proposta apresentada por Sen (1979a, 1985) é de que o bem-estar pode ser visto em termos de como uma pessoa pode funcionar.

Sen (1979a, 1985) critica o Utilitarismo não só pela base informacional singular, mas também por ser uma visão restrita a análise dos bens e por não se preocupar com a forma como os indivíduos utilizam estes bens e quais as suas reais necessidades. Além disso, negligencia a diversidade humana e as variações na forma como cada indivíduo dispõe dos bens que têm acesso, dadas as suas características pessoais.

A pluralidade informacional está no fato de a abordagem proposta por Sen (1979a, 1985) considerar além do aspecto de bem-estar, o aspecto de agência e associar ambos aos dois elementos que compõem a Abordagem das Capacitações, liberdade e realização. A liberdade não está ligada somente a busca pelo bem-estar, há situações em que a liberdade é utilizada para o exercício da agência individual, isto é, casos em que a decisão sobre o que realizar não tem como finalidade única o bem-estar próprio.

A Abordagem das Capacitações deixa de lado os estados mentais vinculados ao consumo de bens para considerar a liberdade de acesso e escolha dos bens e a forma como estes são utilizados pelas diferentes pessoas. A liberdade é de fundamental importância para a análise do bem-estar feita por Sen $(1985,2008,2010)$, por isso, a subseção abaixo focaliza a conceituação de liberdade adotada pela Abordagem das Capacitações.

\subsection{Liberdade: o conceito norteador da Abordagem das Capacitações}

Sen (1987) ressalta a importância da liberdade para que o indivíduo possa levar uma boa vida. Essa liberdade corresponde a possibilidade de o indivíduo poder escolher, ser e fazer o que considera de valor para si. Sen (1987) distingue as liberdades positivas das liberdades negativas6 e o valor intrínseco do papel instrumental da liberdade. Este artigo se detém na liberdade positiva, pois, é sobre ela que está o enfoque da abordagem seniana.

A liberdade positiva (freedom to) refere-se a ter o controle sobre a própria vida (YUPANQUI, 2011). “O sentido 'positivo' da palavra 'liberdade' tem origem no desejo do indivíduo de ser seu próprio amo e senhor" (BERLIN, 1981, p. 142). O indivíduo é capaz de pensar e agir conforme a sua opinião e consegue explica-la

\footnotetext{
A discussão sobre liberdades positiva e negativa iniciou com Isaiah Berlin (historiador, nascido na Letônia em 1909) que, segundo Yupanqui (2011), apesar de não ter criado os termos, foi o primeiro autor a fazer uma divisão clara entre eles. Para obter informações sobre a liberdade negativa, ver Berlin (1981, 2002).
} 
de acordo com a sua própria base de ideias e objetivos (BERLIN, 1981). A liberdade positiva é vista em termos de atual habilidade de uma pessoa para realizar funcionamentos valorados (SEN, 1987).

No âmbito do valor, a relevância instrumental da liberdade refere-se a seu papel como meio para a realização dos fins valorados pelo indivíduo, já o valor intrínseco está na liberdade em si como o fim valorado (SEN, 1987). Sen (2010) elenca cinco tipos de liberdades instrumentais: as liberdades políticas (democracia, liberdade de imprensa), facilidades econômicas (recursos econômicos para consumo e produção), oportunidades sociais (saúde e educação), garantias de transparência (direito a verdade, revelação de informações) e segurança protetora (benefícios para desempregados e demais necessitados).

As liberdades instrumentais contribuem para a capacitação geral de um indivíduo, as capacitações correspondem as liberdades substantivas que podem ser entendidas como liberdades que possuem valor intrínseco, isto é, que possuem valor por si, tal concepção, segundo Sen, (1987), tem sido negligenciada pela literatura tradicional.

Segundo Sen (2010), a expansão da liberdade é o fim primordial e o principal meio do desenvolvimento. Desta forma, uma proposta de desenvolvimento, baseada na expansão das liberdades humanas, deve buscar a eliminação de possíveis privações que os indivíduos enfrentem. Sen $(1987,2010)$ discorre sobre o papel instrumental, mas é no valor intrínseco que a Abordagem das Capacitações se diferencia, pois, a liberdade substantiva do indivíduo corresponde ao fim que deve ser avaliado na análise do bem-estar humano.

A liberdade permite ao indivíduo escolher dentre os funcionamentos passíveis de realização, por exemplo, Sen (1985) contrapõe o caso de duas pessoas famintas, A e B. A é muito pobre e não possui os meios para adquirir os alimentos e $\mathrm{B}$ faz jejum por escolha devido a suas crenças religiosas. Ambas têm o mesmo nível de bem-estar, pois A e B encontram-se subnutridos. No entanto, a pessoa B poderia ter escolhido um estilo de vida alternativo, alimentar-se, pelo qual a pessoa $\mathrm{A}$ não teria a oportunidade de optar (SEN, 1985).

Conforme Sen (1985) a abordagem moral pode ser analisada sob dois aspectos, o aspecto de bem-estar e o aspecto de agência. Eles se complementam, há uma relação de reciprocidade, a agência influencia o bem-estar e o estar bem ajuda na habilidade para agir em busca de outros objetivos, mais amplos (SEN, 1985). Ambos os aspectos se ramificam em liberdade e realização (Quadro 1). A liberdade de agência corresponde à liberdade geral do indivíduo para fazer e realizar os valores e objetivos que considera importantes. Já a liberdade de bem-estar é específica, voltada ao exercício da busca pelo bem-estar, há um único objetivo.

Sen (1985) destaca que, apesar da importância intrínseca do bem-estar, ela não é a única variável a ser considerada na análise moral, por isso, da necessidade de inclusão do aspecto de agência. O aspecto de bem-estar de um indivíduo está relacionado ao vetor de funcionamentos que ele pode realizar, conforme o que con- 
sidera de maior valor para a sua vida. Já o aspecto de agência volta-se a avaliação do que um indivíduo pode fazer de acordo com a sua concepção de bem, o que pode não necessariamente estar relacionado à busca e a realização do benefício próprio.

Quadro 1 - Aspectos de bem-estar e de agência.

\begin{tabular}{|c|c|}
\hline Realização de bem-estar & Liberdade de bem-estar \\
\hline Realização de agência & Liberdade de agência \\
\hline
\end{tabular}

Fonte: Elaboração própria a partir de Sen (1985).

O indivíduo pode exercer sua liberdade de agência e não aumentar o seu bem-estar, ambas as liberdades e realizações apresentadas no Quadro 1 podem se mover em sentidos contrários (SEN, 1985, 2008).

O exemplo das duas pessoas famintas (Sen, 1985) mostra que também pode haver oposição entre a liberdade de bem-estar e a realização de bem-estar, segundo e primeiro quadrante, respectivamente, do Quadro 1. As duas pessoas têm a mesma realização de bem-estar, fazer jejum, mas a liberdade de bem-estar das duas é distinta, a pessoa A não pode escolher alimentar-se como a pessoa B o pode fazer, caso assim deseje.

O objetivo de Sen (1979a, 1985, 1990, 1993, 2010) é sair do campo de análise restrito aos bens e avaliar de que forma esses bens são utilizados pelos indivíduos para realizar os beings and doings valorados, são meios que tem como fim último a expansão das liberdades humanas. A Abordagem das Capacitações corresponde a uma extensão dos bens primários de John Rawls (1971) com um caráter não "fetichista", isto é, sem colocar a atenção apenas sobre os recursos, os meios, mas sim, sobre a liberdade que o indivíduo tem para escolher quais funcionamentos realizar de posse desses bens (SEN, 2003a).

A preocupação de Sen $(1979 a, 1985,1990)$ refere-se às variações interindividuais na relação entre recursos e liberdades. Essas variações podem estar associadas aos diferentes fins e objetivos que os indivíduos possuem e as distintas habilidades para converter recursos em liberdades, gênero, idade e dotações genéticas, por exemplo, podem levar a resultados diferentes a partir do mesmo pacote de bens primários (SEN, 1990).

A forma como se dá o processo de conversão dos bens em funcionamentos passa a ser central para que o bem-estar dos indivíduos possa ser analisado e o desenvolvimento humano avaliado. Verificar se, de fato, houve a realização dos beings and doings relacionados aos recursos corresponde a analisar se o indivíduo teve a liberdade de convertê-los da forma como gostaria.

$\mathrm{Na}$ sequência, os funcionamentos, as capacitações e os intitulamentos, os elementos que constituem a Abordagem das Capacitações e são embasados no conceito de liberdade definido nesta seção, são apresentados. 


\title{
2.2 Elementos constituintes da Abordagem das Capacitações
}

Os funcionamentos correspondem a atividades (comer, ver) ou estados (estar bem nutrido, ser livre politicamente) e a realização destes a partir de bens ou serviços é condicionada pelas características pessoais que variam de um indivíduo para o outro. A característica central do bem-estar, de acordo com a Abordagem das Capacitações, é a habilidade para realizar funcionamentos valorados (SEN, 1985). A capacitação corresponde à liberdade para realizar e os funcionamentos referem-se à realização do bem-estar.

Os funcionamentos correspondem a partes do estado de uma pessoa, as coisas que ela quer fazer ou ser ao longo de sua vida (SEN, 1993).

\begin{abstract}
O conceito de 'funcionamentos', que tem raízes distintamente aristotélicas, reflete várias coisas que uma pessoa pode considerar valioso fazer ou ter. Os funcionamentos valorizados podem variar dos elementares, como ser adequadamente nutrido e livre de doenças evitáveis, a atividades ou estados pessoais muito complexos, como poder participar da vida da comunidade e ter respeito próprio. (SEN, 2010, p. 104)
\end{abstract}

Os funcionamentos valorados variam de acordo com a posição social a qual os indivíduos observados pertencem. Uma pessoa com renda monetária alta pode valorar a liberdade de expressão enquanto uma pessoa com renda monetária baixa pode considerar de maior relevância para a sua vida ter o que comer.

Conforme Sen (2008, p. 80), o conjunto capacitário corresponde a liberdade substantiva (apresentada na seção anterior) da pessoa para escolher dentre vidas possíveis, os vetores de funcionamentos que estão ao seu alcance. Os funcionamentos correspondem a, por exemplo, estar nutrido adequadamente, ter boa saúde, evitar a morte prematura, saber ler e fazer cálculos aritméticos, ter participação política e liberdade de expressão (SEN, 2010). Os funcionamentos são os elementos que constituem o bem-estar; a liberdade para buscá-los refere-se à capacitação (SEN, 2008).

No caso do consumo de alimentos e o funcionamento de estar bem nutrida, a relação entre eles dependerá de fatores como metabolismo, gênero, tamanho corporal, nível de atividade, presença de doenças parasitológicas, acesso a serviços de saúde, conhecimento nutricional, entre outras influências, ou seja, dependerá da capacitação do indivíduo para funcionar (SEN, 1985, 2010). Na Figura 1 é apresentada a representação da Abordagem das Capacitações. 
Figura 1 - Representação não dinâmica estilizada do grupo de capacitações de um indivíduo e o seu contexto social e pessoal.

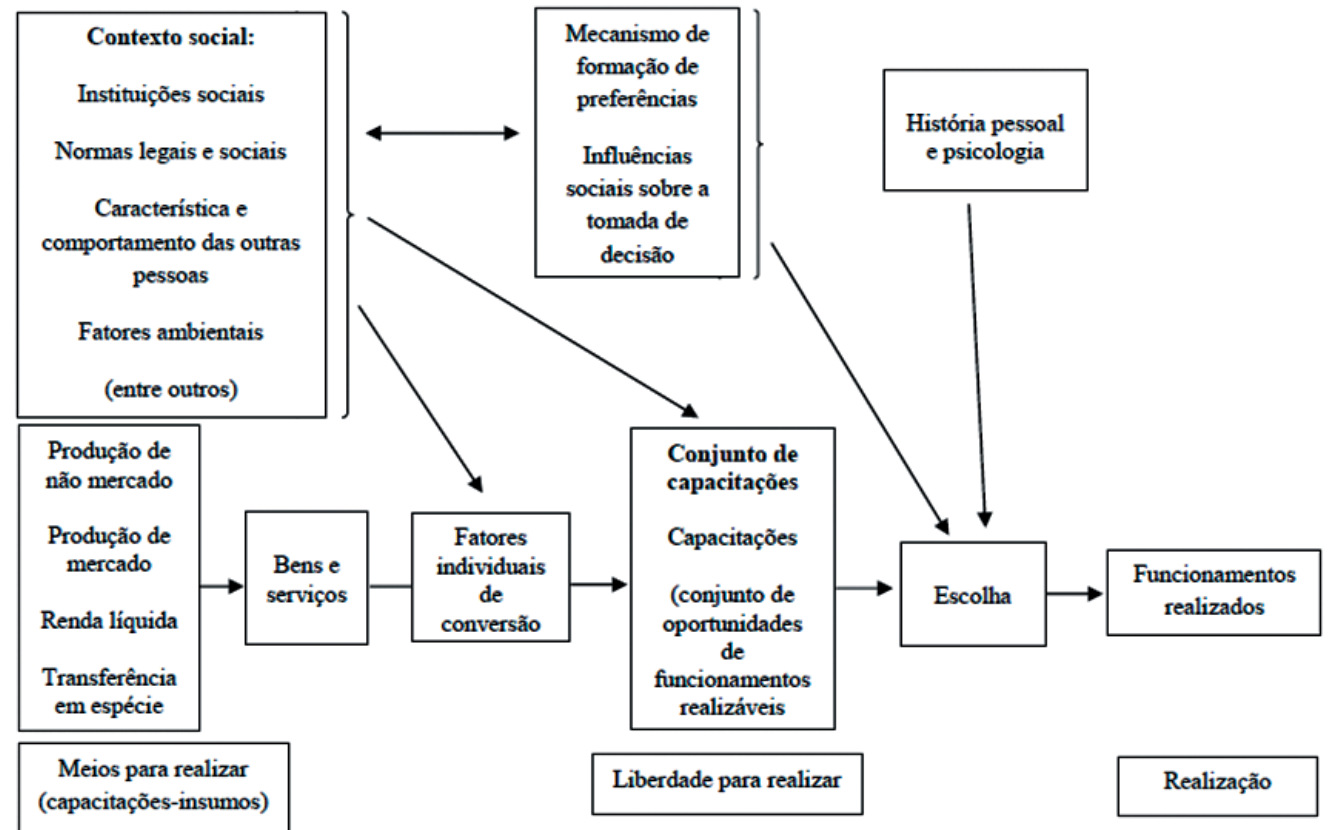

Fonte: Robeyns (2005, p. 98).

Sen (2010) elenca cinco fontes distintas de variação entre a renda e a vantagem que dela se obtém, isto é, cinco fatores principais que interferem neste processo de transformação: as heterogeneidades pessoais (metabolismo, gênero, tamanho corporal); diversidades ambientais (doenças específicas de regiões mais quentes, frio, inundações); diferenças de perspectivas relativas (pessoas pobres em relação às pessoas de uma comunidade rica podem ter dificuldade de participar da vida da comunidade) e; distribuição na família (como a renda familiar é distribuída entre os diferentes objetivos dos membros da família).

$\mathrm{Na}$ sequência, a questão do acesso é descrita sob a perspectiva de Amartya Sen (1981). Para que o indivíduo possa exercer a sua capacitação, é necessário que lhe seja oportunizado o acesso aos recursos a serem convertidos nos fins valorados, adentra-se aqui no campo de análise dos intitulamentos.

A proposta de intitulamentos de Sen $(1981,1997,2010)$ pode ser vinculada a esta ideia de acesso às oportunidades sociais. $\mathrm{O}$ intitulamento de um indivíduo corresponde ao conjunto de pacotes alternativos de bens e serviços que podem ser adquiridos com os recursos legais (dotação) facultados a este indivíduo (SEN, 1997, 2010). O intitulamento total corresponde ao somatório da propriedade (dotação) 
com a possibilidade de troca (SEN, 1997).

Sen (1981) utiliza a ideia de intitulamentos para analisar as fomes coletivas que ocorreram no século XX (Bengala, Etiópia e Bangladesh). Para ele, a fome não está relacionada à escassez de alimentos, mas sim à falta de recursos dos indivíduos para produzi-los ou adquiri-los (terras ou renda). A capacitação de um indivíduo estar bem nutrido depende dos direitos e das oportunidades que ele possui para comandar os recursos necessários a aquisição de alimentos.

Se o indivíduo acessa o serviço educacional e usufrui dos seus benefícios, esse serviço se torna um intitulamento que contribui para o aumento do bem-estar humano e amplia as liberdades e possibilidades de escolha individuais. O Estado pode colaborar com o processo de "distribuição", ou melhor, provimento de intitulamentos conforme a reivindicação, as necessidades das pessoas, como ocorre, por exemplo, com a disponibilidade de recursos para beneficiar os desempregados ou as pessoas em situação de vulnerabilidade social, que possuem baixa renda (SEN, 1998).

A provisão da educação pelo Estado pode ser vista como a criação da dotação para aqueles que não têm os recursos necessários para acessar a educação, para pagar os professores, o material escolar e o transporte. Quando o indivíduo possui a dotação e utiliza o recurso em prol de seu bem-estar, esses recursos tornam-se intitulamentos que expandem as suas liberdades, atingem o propósito de ampliar as suas capacitações. Criada a oportunidade, o indivíduo pode ter a liberdade para acessá-la e assim buscar a realização dos funcionamentos relacionados à educação, como ler e escrever.

$\mathrm{Na}$ seção três, a educação é retratada de acordo com a percepção que a Abordagem das Capacitações possui a respeito de seu papel na vida dos indivíduos.

\section{A educação na Abordagem das Capacitações de Amartya Sen}

A ideia por trás do significado da palavra educar é de que a educação permite aos indivíduos conhecer o mundo ao seu redor. E tal conhecimento não se esgota nas salas de aula, a educação não se restringe a formalidade, essa se relaciona com os processos de aprendizagem não formal (trabalho em grupo fora da escola) e informal (colegas, mídias), e sob esta ótica de inter-relações que ela deve ser vista (ANDRESEN, OTTO \& ZIEGLER, 2010).

O processo de aprendizagem é vasto, ele começa quando o indivíduo nasce e se estende por toda a sua vida, inicia no convívio familiar, avança com o ensino escolar, com a interação entre colegas e continua de acordo com as experiências que cada um vivencia. A educação formal caracteriza-se como um modelo de educação organizado e estruturado de acordo com um conjunto de leis e normas, com um currículo rígido que considera objetivos, conteúdos e metodologia (DIB, 1988).

"A aprendizagem não se circunscreve a uma etapa concreta da vida nem ao 
contexto da escola, mas começa desde o nascimento, até antes, continua por toda a vida e tem lugar em numerosos âmbitos, não necessariamente escolares" (UNESCO, 2008, p. 32). Esse trecho da publicação da UNESCO ressalta o papel da educação sob outras perspectivas, informal e não formal, no desenvolvimento do indivíduo, não é somente a partir da educação obtida em instituições escolares que se "constrói” o conhecimento de uma pessoa.

Ao longo da sua vida, a convivência com as outras pessoas, as características do meio, a cultura, o idioma e as normas sociais também modelam o seu conhecimento. $\mathrm{O}$ conhecimento pode ser adquirido em visitas a museus, ao ouvir rádio ou assistir programas de TV sobre temas científicos ou educacionais, na leitura de textos científicos em jornais ou revistas, na participação em concursos científicos e em palestras e conferências. Essas possibilidades de aquisição de novos saberes são definidas como educação informal (DIB, 1988). E a educação não formal é caracterizada pelo conhecimento adquirido fora da escola, em eventos, conferências e viagens.

Essas diferentes formas que a educação assume se complementam e conduzem o desenvolvimento do conhecimento de cada indivíduo ao longo de sua vida. $\mathrm{O}$ direito à educação deve ser assegurado e respeitado, para que sejam garantidas as liberdades valoradas pelos indivíduos (UNDP, 2000).

If human development focuses on the enhancement of the capabilities and freedoms that the members of a community enjoy, human rights represent the claims that individuals have on the conduct of individual and collective agents and on the design of social arrangements to facilitate or secure these capabilities and freedoms (UNDP, 2000, p. 20).

O relatório de acompanhamento do programa Educação para Todos, publicado pela UNESCO em 2002, aponta que, além da percepção da educação como um direito, ela pode ser inserida no contexto de análise da Abordagem das Capacitações, na qual é considerada relevante por no mínimo três razões. A primeira razão se refere às habilidades de leitura e escrita que a educação primária propicia, as quais são valoráveis por si mesmas, como um resultado do desenvolvimento. A segunda é por poder ajudar a eliminar outras características mais negativas da vida (educação primária livre e compulsória reduzirá o trabalho infantil). E a terceira razão é que a educação tem um papel de empoderamento na vida daqueles que enfrentam múltiplas dificuldades (mulheres que acessem a educação sobrevivem mais e melhor) (UNESCO, 2002).

A educação universal, realizada por todos e não discriminatória, tem impacto social e econômico e é fundamental para a realização das liberdades humanas (UNESCO, 2002). O relatório da UNDP (2000) sobre direitos humanos e desenvolvimento humano apresenta argumentos que confirmam importância de garantir o acesso aos direitos humanos para que os indivíduos possam ter a liberdade de realizar os funcionamentos valorados para a sua vida. 


\subsection{A educação para Amartya Sen}

A habilidade para exercer a liberdade é dependente da educação, por isso da relevância de se analisar a relação entre a educação e a Abordagem das Capacitações (SEN, 1989). Sen (1989) destaca que a expansão da educação possui vários papéis. Ter mais educação influencia a produtividade, contribui para a melhor distribuição da renda nacional entre diferentes pessoas, ajuda na conversão de renda e recursos em diversos funcionamentos e, colabora para a escolha inteligente entre os distintos tipos de vida que uma pessoa pode levar (SEN, 1989).

Em Sen \& Anand (1997), o analfabetismo aparece como uma forma de privação educacional. A proporção da população que não sabe ler e escrever serve como parâmetro de avaliação da incidência dessa privação no grupo analisado. Para que tal privação seja eliminada, a provisão de bens públicos é de extrema importância.A possibilidade de acesso a serviços educacionais permite que o indivíduo possa realizar os funcionamentos associados à educação, neste caso, saber ler e escrever (SEN, 1988; SEN \& ANAND, 1997).

O analfabetismo tem efeitos negativos na vida dos indivíduos e Sen (2003b) apresenta algumas consequências deste tipo de privação educacional. A primeira delas é a insegurança, a privação ocorre e não há oportunidade para que o indivíduo evite tal fato. Não acessar a educação básica também implica em dificuldade para conseguir um trabalho, um emprego que seja vantajoso em termos monetários. $\mathrm{O}$ analfabetismo limita a compreensão e a utilização dos direitos legais, no caso das mulheres, a privação educacional torna ainda mais insegura suas vidas por elas desconhecerem os seus direitos, pois, quando submetidas a situações de violência ou exploração elas não sabem a quem recorrer.

Outra consequência negativa do analfabetismo apresentada por Sen (2003b, 2010) é a barreira que se impõe aos oprimidos no que tange as oportunidades políticas, o indivíduo é impedido de ter voz ativa e participação no processo de definição dos objetivos a serem alcançados pela gestão pública no que se refere a realização do bem-estar. Para que o indivíduo possa participar de um processo de escolha é necessário um grau de instrução básico, a negação desta oportunidade a qualquer grupo é contrária às condições fundamentais da liberdade participativa (SEN, 2010).

A importância da alfabetização está, principalmente, no empoderamento que ela propicia às mulheres; permite a elas reduzir as desvantagens em relação aos homens quanto à sobrevivência que ainda predomina em países em desenvolvimento (SEN, 2010). Além disso, o empoderamento das mulheres culmina na redução da fecundidade e da mortalidade infantil.

A expansão das oportunidades sociais facilita o desenvolvimento econômico com melhor nível de emprego e cria um ambiente favorável para a redução das taxas de mortalidade e para o aumento da expectativa de vida (SEN, 2010). As variações que ocorrem entre um país e outro no que se refere à expectativa de vida se devem as oportunidades sociais que são oferecidas a população, dentre as quais estão as facilidades educacionais.

A educação básica gera benefícios que vão além do indivíduo que recebe a educação, pode provocar mudanças sociais como, a redução da fecundidade e da 
mortalidade, além, do progresso econômico (SEN, 2010). Os benefícios estendem-se para as outras pessoas que são próximas a quem recebe a educação (SEN, $2003 \mathrm{~b}$ ). Os pais, ao colocarem os seus filhos na educação básica, permitem que estes cresçam sem as deficiências pelas quais os pais passaram (SEN, 2003c). A educação deve ser acessada por todos e o conteúdo da educação deve ser voltado à expansão do conhecimento e do horizonte de possibilidades de escolha dos indivíduos (SEN, 2003b).

Estas diversas implicações do analfabetismo, destacadas por Sen (2003b, 2010), retratam a relevância do acesso à educação, não ter esta oportunidade limita as liberdades substantivas futuras do indivíduo e impede que ele realize funcionamentos básicos como saber ler, escrever e desenvolva as habilidades de compreensão e julgamento das informações.

Ao se retomar o conceito de liberdade positiva, definido por Berlin (1981), adaptado e compartilhado por Sen (1987), a liberdade como a possibilidade de escolha do ser ou fazer (being and doing) valorado pelo indivíduo (a atual habilidade para realizar funcionamentos valorados), tem-se que a educação corresponde à liberdade positiva e, como tal, pode assumir a forma de liberdade substantiva, além de seu valor instrumental.

Perceber a educação como uma liberdade substantiva significa destacar seu valor intrínseco, como uma realização em si, por dotar o indivíduo de habilidades que se tornam inerentes a ele como ler, escrever, compreender, dialogar, argumentar e julgar. Essas habilidades correspondem aos beings and doings valorados pelo indivíduo.

\subsection{A educação e as Capacitações}

Hoffman (2006) destaca que, por meio da educação, as crianças e os adolescentes têm desenvolvidas habilidades que os ajudam a pensar crítica e criativamente, resolver problemas, tomar decisões, gerenciar novas situações e comunicar-se de forma eficaz.

Bakhshi, Hoffman \& Radja (2003), ao se referirem à legalidade do direito à educação, afirmam que um direito que é reconhecido pelo Estado, mas que não pode ser exercido, não é suficiente. Se a educação não pode ser acessada, ela não se torna um intitulamento, como visto subseção 2.2 da seção anterior. Um direito que não se efetiva, não é convertido em realização dos objetivos da pessoa.

No processo de conversão de recursos em funcionamentos, a educação apresenta fundamental importância em, no mínimo, três diferentes níveis da determinação do bem-estar, como fim, meio e fator de conversão (CHIAPPERO-MARTINETTI \& SABADASH, 2014). Educação e conhecimento como fim representam o resultado da transformação dos recursos educacionais (escolas e professores) em funcionamento, ressalta o valor intrínseco da educação. As características individuais e os fatores externos (nível de educação dos pais, normas sociais e culturais) influenciam a conversão dos meios em liberdade para realizar.

Educação como meio, segundo Chiappero-Martinetti \& Sabadash (2014), está ligada à sua instrumentalidade na realização de outros funcionamentos, por exemplo, a educação colabora para a definição da posição que o indivíduo ocupa no seu emprego, 
conforme a sua qualificação e as suas habilidades lhe é destinado um cargo.

Uma terceira função desempenhada pela educação no processo de liberdade e realização de bem-estar (segundo e primeiro quadrantes do Quadro 1, respectivamente) é como fator de conversão (CHIAPPERO-MARTINETTI \& SABADASH, 2014). O conhecimento adquirido é incorporado pelo indivíduo de tal forma a tornar-se uma característica pessoal que determina a sua habilidade de converter recursos em resultados.

O cumprimento dessa terceira função pela educação pode ser observado nos cuidados com a saúde e nas decisões sobre a fertilidade (CHIAPPERO-MARTINETTI \& SABADASH, 2014). A educação e o conhecimento colaboram para que a mulher tenha melhores condições para cuidar de sua saúde e de seus filhos e utilize de forma adequada os métodos contraceptivos, o que reduz o número de filhos por mulher e a taxa de mortalidade infantil.

A educação materna gera benefícios que vão além dela como indivíduo, estendem-se aos seus filhos, que terão, no maior conhecimento delas, uma base para levar uma vida mais saudável, com condições monetárias superiores e melhores oportunidades, elementos que colaboram para que o indivíduo tenha uma vida mais longa (SAITO, 2003).

No Quadro 2 são apresentados dados de alguns países para ilustrar o papel da educação como fator de conversão para o caso das mulheres, o que já havia sido afirmado por Sen (2010). Mas é importante salientar que os dados referentes a anos de estudo não captam todas as facetas da educação, pois, como foi ressaltado na terceira seção, ela não se restringe ao âmbito formal, a convivência com outras pessoas também colabora para a formação do indivíduo. E tanto a educação formal quanto a informal são influenciadas pelo contexto social, político e cultural.

Quadro 2 - Informações sobre a educação feminina, fecundidade e mortalidade infantil de regiões e países selecionados.

\begin{tabular}{|c|c|c|c|c|c|c|}
\hline & \multicolumn{2}{|c|}{$\begin{array}{c}\text { Média de anos de } \\
\text { estudo das mulheres }\end{array}$} & \multicolumn{2}{c|}{ Taxa de fecundidade } & \multicolumn{2}{c|}{$\begin{array}{c}\text { Taxa de mortalidade } \\
\text { infantil }\end{array}$} \\
\hline Ano & 2001 & 2011 & 2001 & 2011 & 2001 & 2011 \\
\hline Afeganistão & $1,2^{*}$ & 1,2 & 7,6 & 5,9 & 91,6 & 72,7 \\
\hline África do Sul & 7,3 & 9,5 & 2,8 & 2,5 & 52,3 & 34,2 \\
\hline Brasil & $6,1^{* * *}$ & 7,1 & $2,1^{* * *}$ & 1,8 & $22^{* * *}$ & 13,6 \\
\hline Croácia & 9,1 & 10,5 & 1,4 & 1,5 & 6,9 & 4,2 \\
\hline Itália & 8,3 & 9,6 & 1,2 & 1,4 & 4,5 & 3,3 \\
\hline
\end{tabular}

* Não há dados disponíveis para o Afeganistão no ano de 2001, então se utiliza a média do período de 2000 a 2012, obtida no relatório da UNDP (2014). **Utilizam-se as informações de 2004 para o Brasil, pois é a partir deste ano que os dados estão disponíveis na UIS para a média de anos de estudo das mulheres é 2004.

Fonte: UIS (2015). 
A escolarização feminina se refere aos anos de estudo das mulheres com 25 anos ou mais. A taxa de fecundidade corresponde ao número médio de filhos por mulher e a taxa de mortalidade infantil ao número de mortes de crianças menores de um ano de idade a cada 1.000 nascidas vivas.

Os países que aparecem no quadro foram selecionados de acordo com a disponibilidade de informações e no caso do Brasil e do Afeganistão por terem sido citados anteriormente. Com a exceção do Afeganistão, país em que a escolarização feminina permaneceu constante, em todos os outros países observou-se o aumento da escolaridade média das mulheres entre 2001 e 2011.

A taxa de mortalidade infantil veio na contramão assim como a taxa de fecundidade, ambas tiveram queda nesse período, somente na Croácia e na Itália houve um pequeno aumento no número médio de filhos por mulher, mas nos dois casos, a taxa permanece inferior a dois (UIS, 2015).

No caso do Afeganistão, tem-se uma situação em que são observadas melhorias nos indicadores referentes à mortalidade infantil e a fecundidade, sem ter havido melhora no indicador relacionado à educação. Sobre essa variável, pode ter existido uma melhora, mas como só se obteve a média para o período, tal evolução deixou de ser captada. Mesmo diante da deficiente base informacional sobre a escolaridade das mulheres afegãs, percebe-se que elas possuem baixa instrução e isto se deve a fatores culturais e políticos do país. A posição da mulher no país é de inferioridade e submissão em relação ao homem.

Em 2011, 6,1 milhões de crianças menores de 5 anos de idade morreram em países de baixa e média baixa renda. Se todas mulheres possuíssem o ensino primário, haveria uma queda de $15 \%$ nesse valor e, no caso de todas terem concluído o ensino secundário, a queda da mortalidade na infância nesses países seria de 49\% (UNESCO, 2013).

A tripla funcionalidade da educação apresentada por Chiappero-Martinetti \& Sabadash (2014) é sintetizada no Quadro 3. Sob a perspectiva da Abordagem das Capacitações, a educação não é apenas um meio (segunda coluna do Quadro 3 ) relacionado a busca de trabalho, ela possui outras funções, já citadas anteriormente, como fim e fator de conversão.

O Quadro 3 serve como referência para a análise das variáveis que compõem a avaliação das funções que a educação desempenha na Abordagem das Capacitações.

Quadro 3 - Funções da educação e variáveis associadas à avaliação de cada uma delas.

\begin{tabular}{|c|c|c|c|}
\hline Foco de análise & $\begin{array}{c}\text { Educação como um } \\
\text { meio }\end{array}$ & Educação como um fim & Educação como fator de conversão \\
\hline Capacitações & $\begin{array}{c}\text { 'ser hábil em trabalhar } \\
\text { ou empreender proje- } \\
\text { tos de trabalho' }\end{array}$ & $\begin{array}{c}\text { 'ser hábil a ser educado e } \\
\text { usar produzir conheci- } \\
\text { mento' }\end{array}$ & $\begin{array}{c}\text { 'ser hábil a participar efetivamente da vida } \\
\text { política e social' }\end{array}$ \\
\hline Mensurada por & $\begin{array}{c}\text { Oportunidades no } \\
\text { mercado de trabalho }\end{array}$ & $\begin{array}{c}\text { Oportunidades educa- } \\
\text { cionais }\end{array}$ & $\begin{array}{c}\text { Oportunidades para participar da vida po- } \\
\text { lítica e social; ter uma vida saudável; etc' }\end{array}$ \\
\hline
\end{tabular}




\begin{tabular}{|c|c|c|c|}
\hline $\begin{array}{l}\text { Funcionamen- } \\
\text { tos }\end{array}$ & $\begin{array}{l}\text { Posição e condições } \\
\text { de trabalho, salários }\end{array}$ & $\begin{array}{l}\text { Habilidades e conheci- } \\
\text { mento adquirido }\end{array}$ & $\begin{array}{l}\text { a) Participação política ativa e efetiva (ser } \\
\text { membro de ou ativo em um partido político) } \\
\text { b) Frequência ou intensidade de relações } \\
\text { sociais, participação em redes sociais } \\
\text { c) Efeito marginal da educação em interesses } \\
\text { políticos expostos } \\
\text { d) Saúde } \\
\text { e) Bem-estar no emprego }\end{array}$ \\
\hline Mensurado por & $\begin{array}{l}\text { - Tipo de emprego } \\
\text { (permanente, tempo- } \\
\text { rário, tempo integral } \\
\text { ou parcial) } \\
\text { - Pensão, acordos }\end{array}$ & $\begin{array}{l}\text { - Realização educacional } \\
\text { - Habilidades } \\
\text { - A sua formação cor- } \\
\text { responde a qualificação } \\
\text { requerida por seu } \\
\text { trabalho? }\end{array}$ & $\begin{array}{l}\text { - Envolvimento em grupos políticos, } \\
\text { religiosos ou de direitos humanos } \\
\text { - Ser parte de grupo de caridade ou de } \\
\text { voluntários } \\
\text { - Ter votado nas eleições passadas } \\
\text { - Fazer exercícios regularmente mesmo } \\
\text { que tenha sido um fumante regular } \\
\text { - Satisfação no trabalho }\end{array}$ \\
\hline $\begin{array}{l}\text { Agência e auto- } \\
\text { nomia }\end{array}$ & $\begin{array}{c}\text { (Considerado } \\
\text { somente implicita- } \\
\text { mente em termo de } \\
\text { comando sobre re- } \\
\text { cursos econômicos) }\end{array}$ & \multicolumn{2}{|c|}{$\begin{array}{l}\text { Hábil em fazer escolhas informadas, ter acesso à informação, ter voz } \\
\text { e ser consciente de seus direitos sociais, políticos e civis. }\end{array}$} \\
\hline $\begin{array}{l}\text { Meios para } \\
\text { realizar }\end{array}$ & $\begin{array}{l}\text { Nível de educa- } \\
\text { ção realizada pelo } \\
\text { sujeito e grau, anos } \\
\text { de experiência, } \\
\text { habilidades profissio- } \\
\text { nais e competências, } \\
\text { políticas de mercado } \\
\text { de trabalho ativa }\end{array}$ & $\begin{array}{l}\text { a) Livre acesso a escola, } \\
\text { qualidade dos indicadores } \\
\text { de escola, outros recursos } \\
\text { (bibliotecas, computa- } \\
\text { dores, etc.); bolsas de } \\
\text { estudo, etc. } \\
\text { b) Leitura de jornais e } \\
\text { livros, recursos de mídia e } \\
\text { culturais, etc. }\end{array}$ & $\begin{array}{l}\text { a) Número de partidos políticos e organi- } \\
\text { zações; acesso à tecnologias de comunica- } \\
\text { ção (proxy para o acesso à informação) } \\
\text { b) Número de redes sociais; acesso à } \\
\text { tecnologias de comunicação (proxy para } \\
\text { o acesso à informação) }\end{array}$ \\
\hline $\begin{array}{l}\text { Fatores de } \\
\text { conversão } \\
\text { Individual } \\
\text { Familiar } \\
\text { Contextual }\end{array}$ & $\begin{array}{l}\text { a) Nacionalidade, } \\
\text { idade, gênero, raça, } \\
\text { habilidades e inap- } \\
\text { tidão } \\
\text { b) Origem social } \\
\text { (ocupação do pai, } \\
\text { família pobre ou não } \\
\text { pobre) } \\
\text { c) Tendências de } \\
\text { taxas de desemprego } \\
\text { específicas, trabalha- } \\
\text { dores involuntários } \\
\text { de tempo parcial, } \\
\text { características do } \\
\text { mercado de trabalho, } \\
\text { dummies regionais } \\
\text { (para disparidades } \\
\text { regionais) }\end{array}$ & $\begin{array}{l}\text { a) Nacionalidade, idade, } \\
\text { gênero, raça, habilidades } \\
\text { e inaptidão } \\
\text { b) Origem social (ocu- } \\
\text { pação do pai, família } \\
\text { pobre ou não pobre) } \\
\text { c) Realização educa- } \\
\text { cional média; razão } \\
\text { estudante/professor }\end{array}$ & $\begin{array}{l}\text { a) Idade, gênero, nível de educação } \\
\text { b) Origem social (educação do pai e da } \\
\text { mãe, família pobre ou não pobre } \\
\text { c) Número de mídias, jornais e acesso à } \\
\text { informação }\end{array}$ \\
\hline
\end{tabular}


Percebe-se a diversidade de funções que a educação possui para a vida de um indivíduo. Além de oportunizar melhor posição e condição de trabalho, permite ao indivíduo desenvolver a sua própria habilidade de produzir conhecimento e utilizá-lo da forma que considerar adequado para levar a vida que valora. Ao internalizar esse conhecimento, torna-se apto a participar da vida política, interagir com outras pessoas e ajudá-las, cuidar de sua saúde, entre outras atividades que são facilitadas quando o indivíduo acessa a educação.

Segundo Savater (2006), a educação colabora para o processo de humanização das pessoas, a convivência com outros seres humanos, colegas e professores permite que os indivíduos desenvolvam as suas habilidades humanas. "Esse caráter humanizador implica que a educação tem um valor em si mesma e que não é unicamente uma ferramenta para o crescimento econômico ou social, ainda que também o seja, como costumava perceber-se a partir de visões mais utilitaristas" (UNESCO, 1990, p. 31).

Diante da importância da educação para a expansão de outras capacitações, Terzi (2007) ressalta que a ausência de oportunidades para ser educado é prejudicial ou desvantajosa ao indivíduo. De acordo com a autora, estudos com crianças selvagens, que viveram na selva ou em cavernas, revelaram que a privação do acesso à aprendizagem informal e à escolarização prejudicou a realização de funcionamentos relacionados à linguagem, à comunicação, à aprendizagem e ao raciocínio. $\mathrm{O}$ não acesso à educação impediu que essas crianças expandissem as suas capacitações.

Essas funções, instrumental e intrínseca, que a educação pode desempenhar na vida dos indivíduos, são retomadas na seção a seguir.

\subsection{Os papéis intrínseco e instrumental da educação formal}

Walker (2010) destaca a importância da liberdade individual de poder escolher levar a vida que o indivíduo valora, sendo que, as políticas públicas, em especial, a política educacional tem essencial papel na expansão dessa liberdade. A educação provê aos alunos a habilidade de reflexão e desenvolvimento de uma postura crítica frente à realidade da vida social presente o que os instiga a participar do processo de busca por melhorias na direção de uma forma desejável por todos (WALKER, 2003).

A educação, para Unterhalter (2003), pode ser considerada sob duas óticas na Abordagem das Capacitações, da realização e da agência, aspectos trabalhados por Sen (1985). Na primeira, a educação pode ser vista como uma forma de funcionamento ou realização, esta perspectiva pode ser representada pela educação escolar, completar quatro anos de educação básica por exemplo.

Já sob a ótica da agência, a educação também pode ser entendida como parte do processo de exercício de agência; permite ao indivíduo desenvolver sua capacidade de compreensão e reflexão sobre o direito que possui de exercer as suas capa- 
citações e, assim, discernir os beings and doings valorados que compõem o conceito de capacitações (UNTERHALTER, 2003).

Os aspectos da abordagem moral de Sen (1985), de bem-estar e de agência foram relacionados à educação por Unterhalter (2003). A liberdade e a realização de agência, conforme o exemplo desses autores, estão vinculados a oportunidade de escolha em si, a frequência nas aulas de alfabetização para adultos e compreensão das informações apresentadas em aula. A liberdade e a condição de bem-estar estão relacionadas às implicações que a escolha tem sobre a vida do indivíduo, os efeitos que as aulas de alfabetização terão sobre as atividades diárias e sobre as futuras escolhas, atitudes e opções de escolha do indivíduo (UNTERHALTER, 2003).

A educação, vista pela perspectiva das capacitações, permite ao indivíduo ampliar o conjunto de funcionamentos possíveis de serem realizados, isto é, expande o seu conjunto capacitário, a liberdade para escolher o que considera de maior valor para a sua vida. "[...] education enhances capability in terms of achieved functionings, hence well-being achievements, as well as in terms of well-being freedoms". (TERZI, 2005, p. 133)

Conforme Walker (2005), a educação funciona como um dos alicerces que permite ao indivíduo realizar os funcionamentos valorados por si, não basta ter a opção de escolha, deve ser criado o suporte para que a escolha possa ser feita. Para Vaughan \& Walker (2012), a educação possibilita ao indivíduo aprender e compreender o que é mais valorado por si mesmo e, assim, construir a sua própria base de valores.

A educação cumpre um papel de extrema importância na expansão das liberdades individuais. A realização de um funcionamento relacionado à educação como, por exemplo, a alfabetização, ampara o indivíduo com as habilidades de leitura e escrita. Como estas habilidades tornam-se inerentes ao indivíduo, a alfabetização pode ser considerada uma característica do indivíduo, fator de conversão, como Chiappero-Martinetti \& Sabadash (2014) definiram.

As habilidades referentes à alfabetização permitem ao indivíduo converter o recurso, uma notícia de jornal em conhecimento ou a compreensão da legislação em liberdade quando uma mulher que sofre violência doméstica opta pelo divórcio (VAUGHAN \& WALKER, 2012). A educação amplia as opções de funcionamentos que podem ser realizados e habilita o indivíduo a julgar, dentre os funcionamentos disponíveis, o que considera mais relevante.

Neste processo de expansão das liberdades de bem-estar dos indivíduos a educação fornecida às crianças permite que ela aprenda a ler, escrever, compreender as informações disponibilizadas por meios de comunicação ou na convivência com outras crianças e julgar as informações e conhecimentos de acordo com a sua base de valores (VAUGHAN \& WALKER, 2012). A possibilidade de escolha de realizar esses funcionamentos associados diretamente aos recursos educacionais reflete a função intrínseca da educação, o conjunto de liberdades substantivas.

Além disso, a educação tem implicações sobre o futuro das crianças (VAU- 
GHAN \& WALKER, 2012). Quando adultas, elas terão acesso a um conjunto capacitário mais amplo, liberdades relacionadas à participação política, reconhecimento de seus direitos civis, uso apropriado das informações sobre cuidados com a saúde, dentre outras. Aqui se percebe a função instrumental da educação.

A partir dessa distinção entre as funções intrínseca e instrumental, pode-se criar uma representação (Figura 2) dessa dupla funcionalidade.

Figura 2 - Representação da educação na Abordagem das Capacitações.

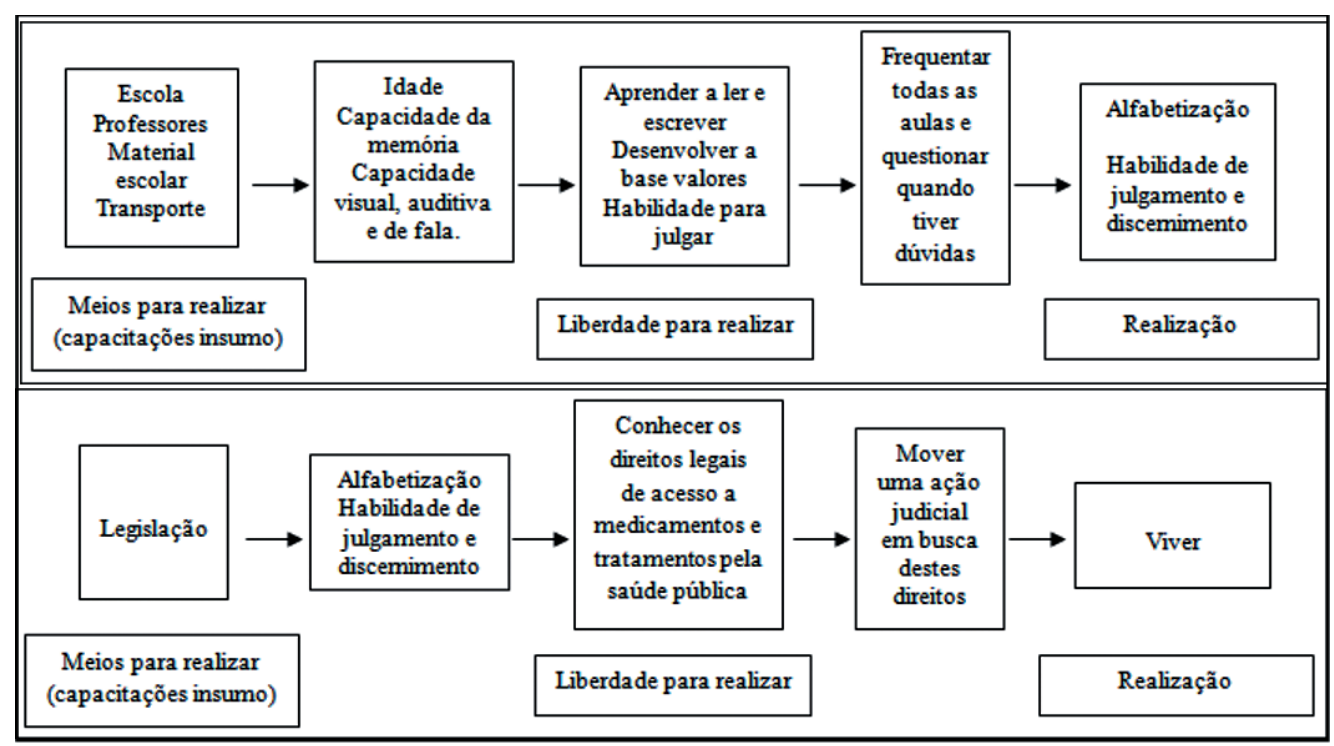

Fonte: Elaboração própria.

O primeiro esquema da Figura 2 descreve a relevância intrínseca da alfabetização, o processo de conversão dos recursos educacionais em habilidades de leitura, escrita e de julgamento. A oportunidade de acessar a educação permite que o indivíduo expanda o conjunto de liberdades relacionadas diretamente a ela, conforme as características do indivíduo e o que ele valora para a sua vida.

O segundo esquema da Figura 2 representa a educação (alfabetização) como uma liberdade instrumental para realizar o funcionamento viver, é observada no caso de um indivíduo que necessite de algum tratamento ou medicamento caro que não seja disponibilizado pela rede pública. Ele tem a possibilidade de acessá-lo, se tiver o conhecimento e a capacidade de interpretar a legislação que trata desses casos. Assim, poderá escolher qual a conduta adequada, condizente com as leis e com as suas necessidades, e realizar o funcionamento que valora a prolongação de sua vida com melhores condições de saúde.

A Abordagem das Capacitações, com referência para a análise da educação, se destaca por considerar que a educação não é somente um meio para aumentar ren- 
dimentos e produtividade, também é instrumental para expandir outras liberdades, mas acima de tudo é uma liberdade substantiva, isto é, é um being or doing valorado por si mesmo. A educação é intrinsecamente importante pelas habilidades que permite ao indivíduo desenvolver leitura escrita, argumentação, julgamento, formação de opinião, entre outras habilidades diretamente relacionadas a ela.

As diferentes formas que a educação assume se complementam para o desenvolvimento da aprendizagem do indivíduo ao longo de sua vida. A junção do processo formal, relacionado à escolarização com o processo informal de aquisição de conhecimento, pela interação entre colegas e pelo acesso a mídias, permite que o indivíduo exerça o controle sobre sua própria vida e assim, realize aquilo que valora.

$\mathrm{O}$ direito à educação deve ser assegurado para que todos os indivíduos possam transformar a realidade a sua volta na busca pelo bem-estar, para que exerçam a liberdade de realizar o que consideram de valor para a sua vida, sem esquecer o respeito e a tolerância em relação ao próximo (UNDP, 2000).

Garantir a oferta da educação, como um direito previsto em lei, significa fornecer as bases para o exercício da liberdade de agência e a possibilidade de os indivíduos escolherem acessar a educação corresponde à realização de agência. Já quando se trata da possibilidade de escolher os funcionamentos vinculados à educação e a realização efetiva, denotam a liberdade e a realização de bem-estar, respectivamente.

O maior nível de escolaridade eleva a compreensão da realidade, consolida opiniões e fornece a base para o indivíduo alterar aquilo que lhe impede de levar a vida que valora, como os cuidados com o meio ambiente, a tolerância frente à diversidade humana e o entendimento de seus direitos.

\section{Considerações finais}

Este estudo teve por objetivo analisar a contribuição da Abordagem das Capacitações de Amartya Sen para a análise do(s) papel(is) que a educação possui na vida dos indivíduos. Para tanto, baseou-se em referencial teórico sobre a abordagem e em revisão bibliográfica que contribuiu para a análise conceitual da educação e para estabelecer a relação entre a educação e a Abordagem das Capacitações.

A importância de se focalizar a educação no âmbito da liberdade é que o ensino e os conhecimentos adquiridos via educação colaboram para que o indivíduo exerça o controle sobre a sua vida, atua como uma liberdade positiva e de valor intrínseco (liberdade substantiva). A educação possibilita ao indivíduo desenvolver habilidades que são relevantes por si só, que não se limitam a ser instrumentais. Permite que o indivíduo aja, escolha, viva da forma que valora. Enfim, a educação pode ser considerada a base da liberdade humana.

A Abordagem das Capacitações permite que a análise do papel desempenhado pela educação na vida dos indivíduos se estenda para além da função instrumental. Essa abordagem não nega que a educação sirva como uma liberdade instrumen- 
tal, mas o seu diferencial está na preocupação com a análise da educação como uma liberdade substantiva, de relevância intrínseca.

Apesar de ainda existirem países em que a educação não é livremente acessada por todos, por questões culturais e políticas ou por falta de investimento no serviço educacional. Tem-se a consciência de que a liberdade humana é desenvolvida pela educação, um somatório dos conhecimentos obtidos na escola e na interação com outros indivíduos.

Para que todos sejam livres, no sentido apresentado pela Abordagem das Capacitações, o Estado deve garantir o direito de acesso aos recursos educacionais, e assegurar que as diferenças humanas sejam respeitadas. $\mathrm{O}$ ensino deve ser universalizado, não discriminatório, e ser amparado na legislação. A diversidade seja religiosa, cultural ou de gênero, deve ser aceita nas instituições de ensino e entre os colegas,

Uma sugestão para estudos futuros seria deter-se no papel desempenhado pela educação em um país. Analisar as informações sobre a educação de uma nação e fazer a associação entre tais resultados e os elementos pertinentes à Abordagem das Capacitações, no caso, a liberdade e as realizações.

\section{Referências}

ANDRESEN, S.; OTTO, H.; ZIEGLER, H. Bildung as Human Development: An educational view on the Capabilities Approach. In: OTTO, H.; ZIEGLER, H. (org.). Capabilities - Handlungsbefähigung und Verwirklichungschancen in der Erziehungswissenschaft. Vs Verlag für Sozialwissenschaften, p. 165-197, 2010.

BAKHSHI, P., HOFFMANN, A.M., RADJA, K. Education and the capabilities approach: Life skills education as a bridge to human capabilities. In: $3^{\circ}$ Conference of the Capability Approach, Pavia. 2003.

BERLIN, I. Dois conceitos de liberdade. In: BERLIN, I. Quatro ensaios sobre a liberdade. Brasília: Editora da Universidade de Brasília. Coleção Ensaio Político, p. 133-175, 1981.

. Liberty: Incorporating Four Essays on Liberty. Oxford: Oxford University Press, 2002.

CHIAPPERO-MARTINETTI, E.; SABADASH, A. Integrating Human Capital and Human Capabilities in Understanding the Value of Education. In: IBRAHIM, S; TIWARI, M. The Capability Approach. Munich Personal RePEc Archive (MPRA), 61800: 06-230. 2014 
DIB, C. Z. Formal, non-formal and informal education: concepts/applicability. In: Cooperative Networks in Physics Education - Conference Proceedings 173. American Institute of Physics, New York, 300-315. 1988.

HOFFMAN, A. M. The Capability Approach and educational policies and strategies: Effective life skills education for sustainable. 2006. Disponível em: $<$ development $<$ www.unece.org/.../ADFCAPABILITYARTICLE.doc $>$. Acesso em: 18 out. 2015.

NUSSBAUM, M. Capabilities as fundamental entitlements: Sen and social justice. Feminist Economics, v. 9, n. 2-3, p. 33-59, 2003. crossrefhttps://doi. org/10.1080/1354570022000077926

. Creating Capabilities: The Human Development Approach. Harvard University Press, Cambridge, MASS, 2011.

RAWLS, J. The Priority of Right and Ideas of the Good. Philosophy E Public Affairs, v. 17 , n. 4 , p. 251-276, 1988.

ROBBINS, L. An essay on the nature and significance of economic science. London: Macmillan \& Co., Limited St. Martin's Street, 1932.

ROBEYNS, I. The Capability Approach: a theoretical survey. Journal of Human Development, v. 6, n. 1, 2005. crossref https://doi.org/10.1080/146498805200034266

SAITO, M. Amartya Sen's Capability Approach to Education: A Critical Exploration. Journal of Philosophy of Education, v. 37, n. 1, 2003. crossref https://doi. org/10.1111/1467-9752.3701002

SAVATER, F. Fabricar humanidad. Revista PRELAC. Santiago: OREALC/UNESCO, n. 2, p. 26-29, feb. 2006.

Sen, A. Equality of what? The Tanner Lecture on Human Values. Standford University, 1979a.

. Utilitarianism and Welfarism. The Journal of Philosophy, v. 76, n. 9, p. 463489, 1979b. crossref https://doi.org/10.2307/2025934

. Ingredients of famine analysis: Availability and Entitlements. The Quarterly Journal of Economics, v. 96, n. 3, p. 433-464, aug. 1981. crossref https://doi. org/10.2307/1882681 
.Well-Being, Agency and Freedom: The Dewey Lectures 1984. The Journal of Philosophy, v. 82, n. 4, p. 169-221, 1985. crossref https://doi.org/10.2307/2026184

. Freedom of choice: concept and content. World Institute for Development Economics Research of the United Nations University, 1987.

. Justice: Means versus Freedoms. Philosophy \& Public Affairs, v. 19, n. 2, p. $\overline{111-121}, 1990$.

. Capacidad y bienestar. In: NUSSBAUM, M. C.; SEN, A. K. (Org.). La $\overline{\text { calidad de vida. Oxford University Press, p. 54-83, } 1993 .}$

. Resources, values and development. Estados Unidos: Harvard University Press, 1997.

. Capital humano y capacidade humana. Revista Cuadernos de Economia, 1998. Disponível em: < http://www.fce.unal.edu.co/media/files/documentos/ ... sen_capital_1998.pdf>. Acesso em: 20 jul. 2014.

. Development as Capability Expansion. In: FUKUDA-PARR S. et al. Readings in Human Development. New Delhi and New York: Oxford University Press, 41-58. 2003 a.

. Reflections on the literacy. In: Literacy as freedom. United Nations Educa-

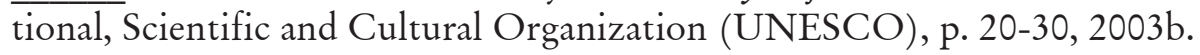

- Amartya Sen: a importância da educação básica. [Entrevista disponibilizada em 28 de outubro de 2003, a Internet]. 2003c. Disponível em: <http://www. theguardian.com/education/2003/oct/28/schools.uk4>. Acesso em: 15 jun. 2015.

. Desigualdade Reexaminada. Rio de Janeiro: Record, $2^{\mathrm{a}}$ ed., 2008.

- Desenvolvimento como liberdade. São Paulo: Companhia das Letras, $2^{\mathrm{a}}$ reimpressão, 2010.

SEN, A.; ANAND, S. Concepts of human development and poverty: a multidimensional perspective. In: Poverty and Human Development: Human Development Papers. New York: United Nations Development Programme, p. 1-20, 1997.

TERZI, L. Equality, capability and social justice in education: re-examining disability and special educational needs. Tese de Doutorado - Institute of Education University of London. Londres, 2005. 
.The capability to be educated. In: WALKER, M; UNTERHALTER, E. (ed.). Amartya Sen's capability approach and social justice in education. Estados Unidos: Palgrave Macmillan, p. 25-43, 2007. crossref https://doi.org/10.1057/9780230604810

UNITED NATIONS DEVELOPMENT PROGRAMME (UNDP). Human Development Report. Human Rights and Human Development. 2000.

. Human Development Report. Sustaining Human Progress: Reducing vulnerabilities and Building Resilience. 2014

. Human Development Report. Work for Human Development. 2015

UNITED NATIONS EDUCATIONAL, SCIENTIFIC AND CULTURAL ORGANIZATION (UNESCO). Declaração Mundial sobre Educação para Todos: satisfação das necessidades básicas de aprendizagem. Jomtien, 1990. Disponível em: $<$ http://unesdoc.unesco.org/images/0008/000862/086291por.pdf>. Acesso em: 27 out. 2015.

. EFA Global Monitoring Report: Is the world on track? 2002.

. Educação de qualidade para todos: um assunto de direitos bumanos. Brasília, $2^{\mathrm{a}}$ ed., 2008.

. EFA Global Monitoring Report: Education transforms lives. 2013.

UNESCO INSTITUTE FOR STATISTICS (UIS). Data Centre, 2015. Disponível em: <http://data.uis.unesco.org/Index.aspx>. Acesso em: 15 dez. 2015.

UNTERHALTER, E. Education, capabilities and social justice. Paper commissioned for the EFA Global Monitoring Report 2003/4, The Leap to Equality, 2003.

VAUGHAN, P; WALKER, M. Capabilities, Values and Education Policy. Journal of Human Development and Capabilities, v. 13, n. 3, 2012 crossref https://doi.org/ 10.1080/19452829.2012.679648

YUPANQUI, M. E. Amartya Sen's Notion of Freedom: A Conceptual History of a Universalist Presumption. Dissertação de Mestrado - University Lund. Lund, 2011.

WALKER, M. Framing social justice in education: what does the 'capabilities' approach offer? British Journal of Educational Studies, v. 51, n. 2, p. 168-187, 2003. crossref https://doi.org/10.1111/1467-8527.t01-2-00232 
. Amartya Sen's Capability Approach and Education. Education Action Research, v. 13, n. 1, 2005.

. The capability approach as a framework for reimagining education and justice. In: OTTO, H.; ZIEGLER, H. (org.). Capabilities - Handlungsbefäbigung und Verwirklichungschancen in der Erziebungswissenschaft. Vs Verlag für Sozialwissenschaften, p. 116-130, 2010.

. A capital or capabilities education narrative in a world of staggering inequalities? International Journal of Educational Development, v. 32, n. 3, p. 384-393, may. 2012.

Recebido em 24.09.16

Aprovado em 05.05.17 